\title{
Who is Influencer and How to Choose the Right One to Improve Brand Reputation?
}

Josef Vodák

University of Žilina, Slovakia

josef.vodak@fri.uniza.sk

Martin Novysedlák

University of Economics in Bratislava, Slovakia

martin.novysedlak@euba.sk

Lucia Čakanová

University of Economics in Bratislava, Slovakia

lucia.cakanova@euba.sk

Miroslav Pekár

University of Economics in Bratislava, Slovakia

miroslav.pekar@euba.sk

The aim of the paper is to provide insight on the emerging community of influencers, which is largely driven by the high impact of social media, has significant power over the perception of brands and companies. These new capabilities require communications professionals who strive for continuous collaboration with target customers through the various social web channels. The paper processed influencers in a well-arranged way, describes its factors and common features for their classification. It describes the main attributes in influencer selection and identification.

Key Words: influencer, categorization of influencers, selection of influencer, brand reputation

JEL Classification: M31, M37

https://doi.org/10.26493/1854-6935.17.149-162

\section{Introduction}

The primary activity of influencers is to influence people, fans, and other individuals who follow their communication, behaviour, and presentation. Any person who comes into the role of influencer has a base of supporters who identify with her attitudes or thoughts or are only under the influence of an influencer. Often the influence that this person has over them does not come from rational beliefs, but from sympathy and personal affection. Regardless of the cause of influencer influence, this is a fact that has some aspects of evaluation and measurement. According 
to these measures, the influencer can be assessed as significant or, conversely, people with limited activity.

In the age of the ubiquitous Internet, influencers are a new type of independent third party that shapes audience attitudes through blogs, tweets, and other social media (Freberg et al. 2011). Through activities that include expressing their opinions, for example, in product reviews, through tips and tricks videos, to organizing competitions and posting images containing products or services (Bernitter, Verlegh, and Smit 2016).

Utilizing a wide range of social media platforms such as Facebook, Instagram, Twitter and YouTube, social media influencers are well suited to publish product information and the latest promotions for online followers (Markethub 2016).

According to Kaplan and Haenlein (2010), influencers publish their posts on different platforms to express:

- their opinions (e.g. TripAdvisor, Amazon);

- inform about their network (e.g. Twitter);

- share their expertise (e.g. Wikipedia);

- express their passions (e.g. personal blogs, Instagram, Pinterest, Facebook).

Influencers thus gain enhanced competencies in creating sophisticated content, form stories, videos and visuals. Given the scalability of the Internet and the speed of dissemination, these influencers can quickly attract mass audiences and achieve 'fame' through the accumulation of cultural capital. We can see this especially in the field of fashion and lifestyle, aesthetics, health, beauty and other areas (McQuarie, Miller, and Phillips 2013).

For example, several fashion artists play an important role in the fashion industry (Wissinger 2015). One of them is Chiara Ferragni, a wellknown Italian influencer thanks to her 'Blonde Salad' blog with 8.2 million Instagram followers. As an influencer, she gains increasing numbers of interested followers who become active and help spread her thoughts through social media (Etter et al. 2018).

\section{Characteristics of Influencer}

Cambridge Dictionary even defines influencers, as a person or group that has the power to influence the behaviour and opinions of others. But this is nothing new. For centuries we have had philosophers, artists, activists. They were influencers of the past. Today, influencer is anyone who has 
the Internet. Add water in the form of fans and wait for sponsors to rise up. Cha-ching, money!

According to a business dictionary, an influencer is an individual who has the power to influence others' decisions through their own authority, knowledge, position, or relationship.

Whether it is marketing, media (such as news and journalism, as well as social media), the role of influencer is becoming increasingly important. Influencers are becoming increasingly important, especially in the time of information technology and social networks, which significantly change the face of both marketing and newscast. The identification of influencer, that is, a personality that is significant in terms of shaping the views of the follow-up groups, is essential. At present, the analysis of the most influential personalities of a particular user segment is a very important component of marketing communication or media performance. Thus, not only on the Internet, there are different lists of individuals who affect other users, whether through social networks, blogs, or other platforms.

Influencers are sort of a modern creative and media agency. They make videos many times by themselves, sometimes they have a small production team, but mostly it is a one man show. And the media agency because when influencer has hundreds of thousands of well-defined and enthusiastic fans, targeting and reach is a breeze. Influencer marketing is nothing new, only the power of social media has joined it - then we are talking about digital influencers (Hrnčárová 2017).

Social influencers are everyday people who influence shopping decisions, using available technologies such as blogs, microblogs, podcasts, social networking sites, etc. (Singh, Lehnert, and Bostick 2012).

Finnish influencer marketing company PING Helsinki defines influencer as a person who writes blogs, publishes their opinions on YouTube, Snapchat, Instagram and other social channels. For example, they may be athletes or artists, but the main element is that they have their community on social media and are open to producing sponsored and professionally produced content for their followers. Influencer marketing can take various forms in blog posts, videos, or images on influencer social network channels, which means content cooperation. It may be content for a marketing campaign of a company with an influencer name or photo, which means providing content. Influencer marketing can also be used for events, travel trips and workshops, widgets and display ads (Biaudet 2017). 
The word influencer is often wrong with the word 'advocate', but their meaning is not the same. Influencers are not customers but encourage brand or product recommendations. On the other hand, advocate is an existing customer who voluntarily recommends a particular brand or product (Brown and Fiorella 2013).

According to Matthews's article on influencing targeting (2013), customers believe third-party recommendations (bloggers and Instagrammer) more than the brand itself. Influencer does not only bring its own followers but also brings a follower network. If influencer has faithful followers, it can also popularize the brand's website, increase exposure and sales of the company's products through their recommendations or stories about the company's product or service experience.

Other sources describe influencers as individuals who have active followers and are able to direct these followers to act (MarketingProfs 2017)

Keller and Fay (2016) talk about influencers as day-to-day consumers who, more than just an average person, are searching for information, sharing ideas, information, and recommendations with other people. It can be done by voluntarily sharing opinions about products, services that they like or are influencers because of their knowledge, advice and opinions.

The word 'influence' comes from the Latin ad vertere, meaning 'flowing from within.' In a social context, it is the ability to influence the character, development, or behaviour of someone or something, an act or power to produce an effect without apparent force or direct command.

\section{Influencer Categorization}

Among the relatively powerful type of influencers in the field of news, but also marketing and other areas of public life are undoubtedly bloggers. They are personalities contributing articles to their own websites that are run on the blog platform. The blog is then a personal space where its creator can insert a variety of information in the form of written text or image and audio-visual documents. Prior to the advent of F B or Twitter networks, blogging has enjoyed great attention. The basic distribution of influencers, according to the size of the followers, can be divided as follows:

- Mega-influencers have more than a million followers. Most often, celebrities who work with big brands are here. These people can be famous, but they do not affect people's behaviour so much. Just be- 
TA B LE 1 Typology of Influencers

\begin{tabular}{ll}
\hline Mega-influencer & Over 1 million of subscribers \\
Macro-influencer & 100,000 to 1 million of subscribers \\
Micro-influencer & 1,000 to 100,000 of subscribers \\
Nano-influencer & Less than 1,000 of subscribers \\
\hline
\end{tabular}

cause you know the name of a celebrity doesn't mean that you respect them enough to buy the products they recommend.

- Macro-influencers have a user base ranging from 100,00o to a million followers, brands and companies choose them as their business partners.

- Micro - influencers have from 1,00o to 100,00o followers.

- Nano-influencers are a group that is expected to have more companies decide to cooperate with them in 2019, even though they have less than 1000 followers but have a huge impact on a relatively narrow market.

- Nano-influencers may seem to have too little influence, that they simply do not have enough supporters, but these influencers are often the best people to pick up a brand or product for a narrow or specific location. If the brand follows the relationship with nanoinfluencers, most people consider it authentic and genuine.

Inkybee marketing software (2016) states that the most important parameter of an influencer is:

- His audience size,

- How often he publishes posts,

- What is his level of engagement.

According to an article called 'Marketers Pair Up with Influencers-and It Works' on web-platform eMarketer (2015), most sellers that use influencer marketing select their influencers based on their social profile and verified attendance data. Site demographic evaluation is a less important criterion in their selection. The surprising finding is that influencers have become almost as important as the traditional opinions of family and friends. 56\% of Twitter users say they rely on friends' recommendations and $49 \%$ of users say they rely on recommendations from influencers (Swant 2016).

However, not all influencers are equivalent. Sellers generally divide influencers into the following categories: 
- celebrities,

- industrial experts and leaders,

- bloggers and various content creators,

- micro-influencers.

Kylie Jenner, with 82.2 million Instagram followers, receives an amount of between $\$ 100,000$ and $\$ 300,000$ for every Instagram sponsored post. Midrange influencers with 400,000 to 1.5 million followers currently earn approximately $\$ 5,000$ for each post. Micro influencers with less than 5,000 followers earn on average less than $\$ 250$ per contribution.

It is precisely marketing-specific content that focuses on a particular product that influencers create and makes it valuable to the brand. Influencers should not only be distributed according to known areas such as food, fashion and entertainment, but can be further divided to reach specific followers/customers.

\section{Selection of Influencer}

Being an influencer means more than just getting a big audience. According to Brown and Fiorella, the current influencer marketing paradigm puts influencer in the centre of marketing space. However, they also talk about the theory of placing the customer and not the influencer in the centre of marketing space. The customer is ultimately the one who makes the decision and not the influencer. Trademarks, their marketing messages, and influencers, according to Brown and Fiorella, are planets that circulate around the customer to take his attention. In the first theory with influencer in the central position of the strategic marketing model, traders need to identify people who have a broad outlook in a community of specific interests.

In the second theory, the customer's position is changed to the centre of the circle and a completely new space is formed. Instead of influencer, a customer is in the centre, with followers being now his friends, family, work colleagues, institutions, media, and communities that influence customer purchasing decisions. However, for both models, the first step is the same, namely the identification of the demographics of the targeted audience and the communities in which they are engaged. Here, however, the similarity of the two models begins and ends.

When communities and influencers are identified, the marketing team tries to educate, encourage and motivate the selected influencer to broadcast and share the brand's message through social channels such as blogs 


\section{FIGURE 1}

Influence Marketing Model with a Customer in the Centre (adapted from Brown and Fiorella 2013)

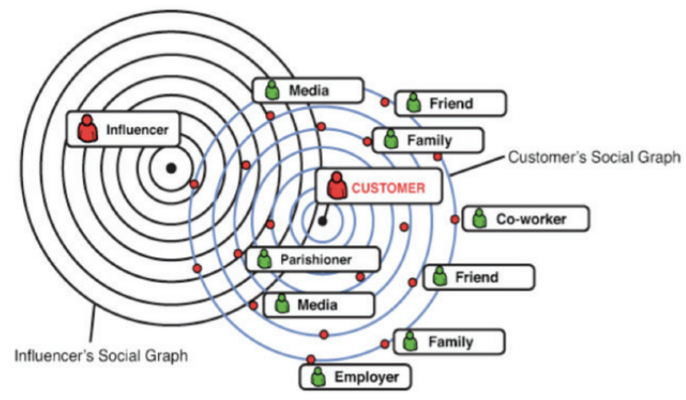

or Facebook. In this way they engage the audience with prizes or encourage them to share with their own social group (Brown and Fiorella 2013).

A guide for businesses, what to look at before working with some influencer is briefly described below.

- Professional background and knowledge. It is quite common to background check a future employee. Influencers should not be an exception. Businesses should look at his education, work, creative competence, image. How people like him. They should be reliable sources of information. This can be tested at an interview or informal debate. Business profiles should always be verified by businesses. I prefer to look at influencers as people we buy service from rather than herd chasers. Ability to produce creative results. The company marketing is strengthened by influencers. They should not just be a competitive advantage, but they should also bring expertise and experience. The impact is measured by the size and value of the response it provokes' says Rachel Miller, an influencer marketing manager at TopRank Marketing. The response must be measurable and increase brand value (Escobedo 2017). Ability to measure brand benefit. In both math and marketing, there should be a balance between the followers of our star's influence and the number of likes/interactions he has on his posts. Someone who is watched by 34,000 people should not only have 700 likes without any comment. If the numbers don't fit, get away from them. It means that influencer is ineffective or has bought fans. Or both. The impact on the audience and the size of the audience should not be confused (Escobedo 2017).

According to Booth and Matic (2011), influencer impact assessment has a wide range of criteria:

- Number of followers per month (number of visits per month). 
- Linking (the number of links to or from a blog).

- Frequency of posts (number of messages/posts over time).

- Blogger media citations (the amount and level of media quoting influencer).

- Industry Score - the number of points it receives from authorities that are key to a sector-related issue (notes, continuity, panel collaboration).

- Evaluation of social cooperation - level of participation in social sites (eg Twitter, other blog communities, LinkedIn, etc.).

- Exposure Index - frequency of responses and observer comments.

- The amount and speed of topic-related posts.

- Qualitative review of posted topics and comments/contributions.

- Identification and suitability of influencer on social networks based on the above variables.

When identifying the right influencer for the company, it is important to know that the chosen name affects the purchase decision. It is important to be specific about what products or services we are considering and what segment is targeted (Brown and Hayes 2008).

An alternative method of identifying the right influencer is to ask those who make decisions, so the company needs to understand exactly what the community is looking for and needs. If it is a multi-productive company, it should have a different set of influencers for each product, in every industrial sector in each country (Brown and Hayes 2008).

To find the right brand influencer, Biaudet (2017) says there are some qualities that influencer should have, such as:

- knowing the product or service and expressing a sincere interest in it,

- should be an expert leader in his area,

- should have the right target audience for the company,

- should know how to produce appropriate content - such as stories, videos, images, posts,

- should understand marketing and be involved in commercial cooperation,

- should have a sufficient number of followers on the relevant social media, 
- should have good cooperative skills and should understand the value of their work.

If a company cannot measure the success of its own influencer marketing practices, they will not be able to improve it. Therefore, it is important to measure and demonstrate the results of practices that enable strategies to be optimized to reach the next stage. If companies invest more in influencer marketing, there is also a growing need to measure success (Dorfman 2015).

However, there are no explicit data in influencer marketing that accurately indicate who influenced whom, at what time, where and how. It is measured according to the purpose and the goal set by the company. If the campaign is focused on growth and the goal of becoming as visible and measurable as possible is the number of new potential customers who have learned about their work through this campaign. Thus, if a campaign is focused on engagement, it is measured in amount depending on the number of 'like,' comments, interactions, video viewing, sharing, or clicks. Engagement is an indicator that shows what customers think about a brand not just about the product (Westwood 2017).

According to Harvard Business Review, $75 \%$ of businesses said that the identification of influencers is the most difficult step in the process of influential marketing (Staden and Niekerk 2018).

Most influencers were found to be identified only on the basis of:

1. their willingness to participate in the campaign,

2. based on tags or keywords such as 'fashion' or 'fitness', to specialized demographic features,

3. their social score.

In a discussion with a representative of a well-known influence company, the above approach was confirmed and added that companies use their internal instincts, historical views, and brand preference as an inclusion criterion (Revfluence 2017).

While much research is being conducted on best practices to identify influential actors on social media platforms, many uncertainties remain. Several digital approaches have been developed to identify these individuals, including providing a 'social score' based on their strong links within the network. However, algorithms are performed randomly based on network links based on diffuse models, without involving personal interest, engagement, or meaning that will be realized on an existing network (Groshek 2017). 
FIGURE 2

Fisherman's Model of Influence

Marketing (adapted from

Brown and Fiorella 2013)

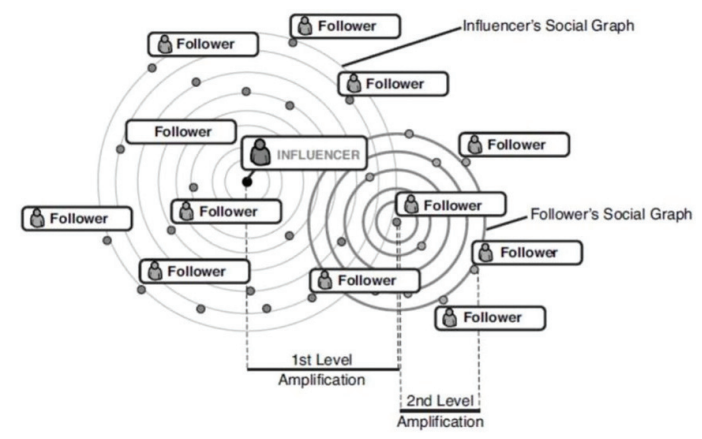

FIGURE 3

Characteristics of Influencer

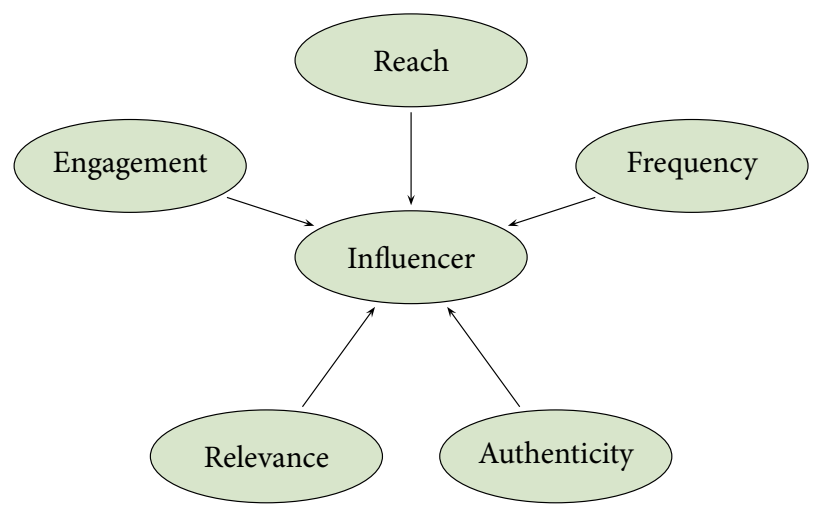

Fisherman's influencer marketing model helps companies identify potential influencers and their communities, and later uses them as a basis for further research and analysis in this regard. Attentive merchants should use Fisherman's influence marketing model as the first step in their marketing plan. This model suggests applying the concept of 'deciding a wider network to catch as many fish as possible, which means influencing the largest social community to achieve purchasing results (Brown and Fiorella 2013).

To identify potential influencers, we should pay attention to the following characteristics - relevance, engagement, reach, frequency, authenticity.

Relevance means how the influencer content is matched to the brand management. A company looking for an influencer should know the posts of that influencer. Engagement is an indicator of the interaction between followers and a given influencer in comments, responses, and sharing. The third characteristic is the reach. Businesses should only consider 
unique profile or blog visitors if they are focusing on reach. Followers are only relevant if influencer reaches the target audience of that brand. Frequency is the fourth characteristic to be considered when searching for a potential influencer. It means how often influencer publishes posts and how often visitors return to him. One post is not enough to achieve that the followers visit also the brands website.

According to Hamann (n.d.), usually more posts and shares are needed to reach this goal. If influencer publishes high-quality content on a regular basis, readers are more likely to return and influencers who do not publish posts often have fewer loyal followers. The last characteristic is authenticity. Influencers who have less sponsored contributions to the platform they use are mostly truer and more authentic. Also, the brand, service, or product in question is more trustworthy for people if influencer adds a personal story or experience to the post instead of the product review itself.

\section{Conclusion}

Influencer marketing is the mainstream, as its effective implementation has a formal impact on the organization's financial as well as strategic policy, regardless of its area of activity. However, the fact remains that each organization requires an individual approach based on many internal as well as external factors that it interacts with when setting their goals.

In an effectively implemented influencer marketing system, each organization should have the following set of areas:

1. What are the requirements for influencer?

2. What channels of communication should be used by the influencer?

3. Which products from our portfolio will fall under the influencer activity?

4. How we measure the ability of influencer to produce creative results?

5. How will we measure the economic and financial contribution of the influencer to the brand or business?

Influencer marketing is a current issue, as it integrates a number of business activities that need to be combined to deliver a functioning and prosperous, long-term business. The choice of influencer marketing is often a challenging and complicated choice that depends entirely on the nature as well as the goals of the organization itself.

The importance and significance of influencer marketing is not continually losing its importance exactly because effective implementation 
is based on continuous mapping of the environment and research that is capable of answering many questions, not only in academic field, but also in practice.

\section{Acknowledgments}

This paper was supported by Slovak Research and Development Agency under contract A PVV-15-0511.

\section{References}

Bernitter, S., P. W. J. Verlegh, and E. G. Smit. 2016. 'Why Nonprofits Are Easier to Endorse on Social Media: The Roles of Warmth and Brand Symbolism.' Journal of Interactive Marketing 33:27-42.

Biaudet, S. 2017. 'Influencer Marketing as a Marketing Tool.' https://www .theseus.fi/bitstream/handle/10024/134139/Biaudet_Sofie.pdf ? sequence $=1$ \&isAllowed $=y 7$

Booth, N., and J. A. Matic. 2011. 'Mapping and Leveraging Influencers in Social Media to Shape Corporate Brand Perceptions.' Corporate Communications: An International Journal 16 (3): 184-91.

Brown, D., and S. Fiorella. 2013. Influence Marketing: How to Create, Manage, and Measure Brand Influencers in Social Media Marketing. Indianapolis, IN: Que Publishing.

Brown, D., and N. Hayes. 2008. Influencer Marketing: Who Really Influences Your Customers? Amsterdam: Elsevier.

Dorfman, J. 2015. 'A Framework for Measuring Influencer Marketing Success.' http://www.traackr.com/blog/measuring-influencer-marketingsuccess

eMarketer. 2015. 'Marketers Pair Up with Influencers - and It Works: Content Creation, Promotion the Leading Tactics For Influencer Engagement.' https://www.emarketer.com/Article/Marketers-Pair-Up-withInfluencersand-Works/1012709

Escobedo, J. 2017. 'Kto je influencer? Návod pre firmy, ako si vybrat' na biznis toho najlepšieho.' https://www.forbes.sk/influencer-navod-firmyvybrat-biznis-toho-najlepsieho/\#

Etter, M., E. Colleoni, L. Illia, K. Meggiorin, and A. D'Eugenio. 2018. 'Measuring Organizational Legitimacy in Social Media: Assessing Citizens' Judgments with Sentiment Analysis.' Business \& Society 57 (1): 60-97.

Freberg, K., K. Graham, K. McGaughey, and L. A. Freberg. 2011. 'Who Are the Social Media Influencers? A Study of Public Perceptions of Personality' Public Relations Review 37 (1): 90-92.

Groshek, J. 2017. 'How Network Analysis Helps Journalists Identify Social Media Influencers.' 2017. http://datadrivenjournalism.net/news_and 
_analysis/how_network_analysis_helps_journalists_identify_social _media_influencers

Hamann, H. n.d. ' 5 Tips for Finding the Right Social Influencers for Your Brand.' http://www.convinceandconvert.com/digital-marketing/5-tips -forfinding-theright-social-influencers-for-your-brand

Hrnčárová, K. 2017. 'Každá značka si vie nájst' influencera, ktorý osloví jej publikum.' https://strategie.hnonline.sk/marketing/961207-kazdaznacka-si-vie-najst-influencera-ktory-oslovi-jej-publikum

Inkybee. 2016. 'The Best Practice Guide for Effective Blogger Outreach.' http://www.inkybee.com/blogger-outreach-a-best-practiceguide/ \#.WKejBzsrKUl

Kaplan, A., and M. Haenlein. 2010. 'Users of the World, Unite! The Challenges and Opportunities of Social Media.' Business Horizons 53 (1): 5968.

Keller, E., and B. Fay. 2016. 'How to Use Influencers to Drive a Word-ofMouth Strategy' https://www.kellerfay.com/how-to-use-influencersto-drive-aword-of-mouth-strategy

Markethub. 2016. 'Influencer Marketing vs Word-of-Mouth Marketing.' https://www.markethub.io/influencer-marketing-vs-word-of-mouthmarketing

McQuarie, E. F., J. Miller, and B. J. Phillips. 2013. 'The Megaphone Effect: Taste and Audience in Fashion Blogging.' Journal of Consumer Research 40 (1): $136-58$.

MarketingProfs.com. 2017. 'The State of Influencer Marketing in 2017'. https://www.marketingprofs.com/charts/2017/31524/the-state-of -influencer-marketingin-2017?adref=nlto20717

Matthews, K. 2013. 'The Definite Guide to Influencer Targeting.' https:// blog.kissmetrics.com/guide-to-influencer-targeting

Revfluence. 2017. '4 Tips For Identifying The Right Influencers.' http://blog .revfluence.com/blog/2017/5/22/3-tips-to-identifying-the-right -influencers?rq=tip

Singh, N., K. Lehnert, and K. Bostick. 2012. 'Global Social Media Usage: Insights into Reaching Consumers Worldwide.' Thunderbird International Business Review 54 (5): 683-70o.

Staden, M., and L. Niekerk. 2018. 'Uncovering the Value of Influencer Marketing through Social Network Analysis and Brand Positioning Insights.' http://www.samra.co.za/wp-content/uploads/Van-StadenVan-Niekerk_Uncovering-the-value-of-influencer-marketing.pdf

Swant, M. 2016. 'Twitter Says Users Now Trust Influencers Nearly as Much as Their Friends.' http://www.adweek.com/digital/twitter-says-usersnowtrust-influencers-nearly-much-their-friends-171367

Westwood, K. 2017. ' 4 Goal-Specific Ways to Measure Influencer Market- 
ing ROI.' http://www.convinceandconvert.com/influencer-marketing/ measureinfluencer-marketing-roi

Wissinger, E. 2015. This Year's Model: Fashion, Media, and the Making of Glamour. New York: NyU Press.

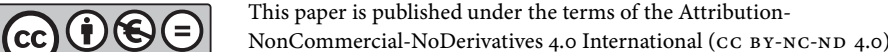

License (http://creativecommons.org/licenses/by-nc-nd/4.o/).
} 